Research Article

\title{
Finite Element Analysis of Residual Stress in Ti-6Al-4V Alloy Plate Induced by Deep Rolling Process under Complex Roller Path
}

\author{
J. J. Liou and T. I. El-Wardany \\ United Technologies Research Center, 411 Silver Lane, East Hartford, CT 06108, USA \\ Correspondence should be addressed to T. I. El-Wardany; elwardti@utrc.utc.com
}

Received 29 July 2014; Revised 25 November 2014; Accepted 26 November 2014; Published 24 December 2014

Academic Editor: Archie Lockamy

Copyright (C) 2014 J. J. Liou and T. I. El-Wardany. This is an open access article distributed under the Creative Commons Attribution License, which permits unrestricted use, distribution, and reproduction in any medium, provided the original work is properly cited.

\begin{abstract}
The kinematics of the deep rolling tool, contact stress, and induced residual stress in the near-surface material of a flat Ti-6Al$4 \mathrm{~V}$ alloy plate are numerically investigated. The deep rolling tool is under multiaxis nonlinear motion in the process. Unlike available deep rolling simulations in the open literature, the roller motion investigated in this study includes penetrative and slightly translational motions. A three-dimensional finite element model with dynamic explicit technique is developed to simulate the instantaneous complex roller motions during the deep rolling process. The initial motion of the rollers followed by the penetration motion to apply the load and perform the deep rolling process, the load releasing, and material recovery steps is sequentially simulated. This model is able to capture the transient characteristics of the kinematics on the roller and contacts between the roller and the plate due to variations of roller motion. The predictions show that the magnitude of roller reaction force in the penetration direction starts to decrease with time when the roller motion changes to the deep rolling step and the residual stress distributions in the near-surface material after the material recovery step varies considerably along the roller path.
\end{abstract}

\section{Introduction}

Deep rolling is a mechanical surface treatment method in which the workpiece surface is exposed to high local mechanical load using a spherical or cylindrical type tool to induce work hardening and compressive residual stress in the near-surface material. Depending upon the controlling parameters, this process alters the mechanical behavior of the material by cold working and enhances stability of the nearsurface structure when the workpiece is exposed to a high temperature condition (exceeding $450^{\circ} \mathrm{C}$ ). The high temperature fatigue resistance is due to the formation of a nearsurface work hardened layer with a nanoscale microstructure during the deep rolling of the surface [1]. In automotive industries, fatigue damage has occurred near the crankshaft fillets due to the stress concentration. Deep rolling has been applied to the crankshaft or shaft fillets to enhance the fatigue strengths of crankshafts [2-4]. In aerospace industries, the initiation and early growth of fatigue cracks, especially in the presence of foreign-object damage, in the turbine engine components is one of the most critical challenges.
Deep rolling provides deeper case of compressive residual stress and a work hardened microstructure as well as a relatively smoother surface finish [1]. During the deep rolling process, the mechanical load is often repeatedly applied on the workpiece surface to continually increase plastic deformations in the near-surface material. In addition, the adaptability of attaching deep rolling tool to a conventional machining center to integrate this process into machining consequences has largely increased the cost effectiveness of the process.

A large number of numerical simulations have been conducted using a spherical or cylindrical type of rolling tools to understand the contact stress distributions and deformation patterns during the near-rolling process, as well as residual stress profiles after the process. Yen et al. [5] conducted 2D plain-strain and 3D finite element (FE) analyses of roller burnishing using a spherical rigid roller loaded on the hardturned elastic-plastic material made of AISI 52100 steel to study the deformation on surface lays and residual stress in the near-surface material. Predictions from Yen et al. [5] show 
that the roughness peak-to-peak value $(\mathrm{Rz})$ can be reduced from 11 to $1 \mu \mathrm{m}$. In the $2 \mathrm{D}$ analysis, the predicted residual stress in the tangential (out-of-plane) direction has the location of a maximum compressive residual stress in agreement with the experiment while the maximum compressive residual stress value is larger than that in the experiment. The predicted maximum compressive residual stress in the axial direction the maximum compressive residual stress is correlated well with the experimental data. However, unlike the experimental curve, the stresses drastically turned into high tensile residual stress when approaching the surface. In the $3 \mathrm{D}$ analysis, the predicted residual stress in the tangential direction is not in agreement with the experiment due to an insufficient thickness in the model.

Sartkulvanich et al. [6] further improved the 2D and 3D FE analyses, concluding that (i) tensile residual stresses predicted from the simulation are due to the plane strain assumption used in the 2D model since the tool is presented as a cylindrical object rather than a spherical object. Line contact is presumed in the 2D FEM simulation rather than point contact that is typically generated by spherical tool. In the $2 \mathrm{D}$ model, the tool geometry, which is assumed to be larger in the axial direction, pushes more material to flow aside and generates more tensile stresses in the axial direction than what is expected from a spherical tool and (ii) the FE analyses and experimental measurements reveal that the burnishing pressure is the most important factor for the amplitude of residual stress.

Ali and Pan [7] used 2D plane-strain finite element analyses to investigate the differences of residual stress and displacement distributions due to single indentation and rolling between a rigid roller and an elastic roller with a very large contact pressure. The elastic-plastic plate is modeled as a power-law strain hardening material with the nonlinear kinematic hardening rule. The residual stress distributions for both roller cases are nearly identical. The values of the residual stresses at the contact surface for both rigid and elastic rollers are about the same except a slightly $(2 \%)$ higher peak near-surface compressive residual stress components in the rolling and out-of-plane directions for the rigid roller while compared to those for the elastic roller. The residual values of the displacement components in the loading direction are nearly the same for both rollers while the residual value of the displacement component in the rolling direction for the rigid roller is slightly higher than that for the elastic roller.

Other similar numerical investigation into this subject can be found in Guagliano and Vergani [8], Choi and Pan $[3,9]$, Majzoobi et al. [10], Fu et al. [11], Sayahi et al. [12], and Klocke et al. [13]. These analyses are modeled with a spherical or cylindrical type of roller under indentation or rolling condition. The conducted literature review indicates the need for a more detailed deep rolling FE model to take into account the multiaxis process kinematics. The present paper attempts to analyze a complex roller motion for the deep rolling which is difficult to be idealized by a simple rolling path on the elastic-plastic plate. The roller considered here is in the cylindrical shape. The roller axis is perpendicular to a mandrel axis. The mandrel rotates around its axis in a constant speed while it moves on the plate in a constant

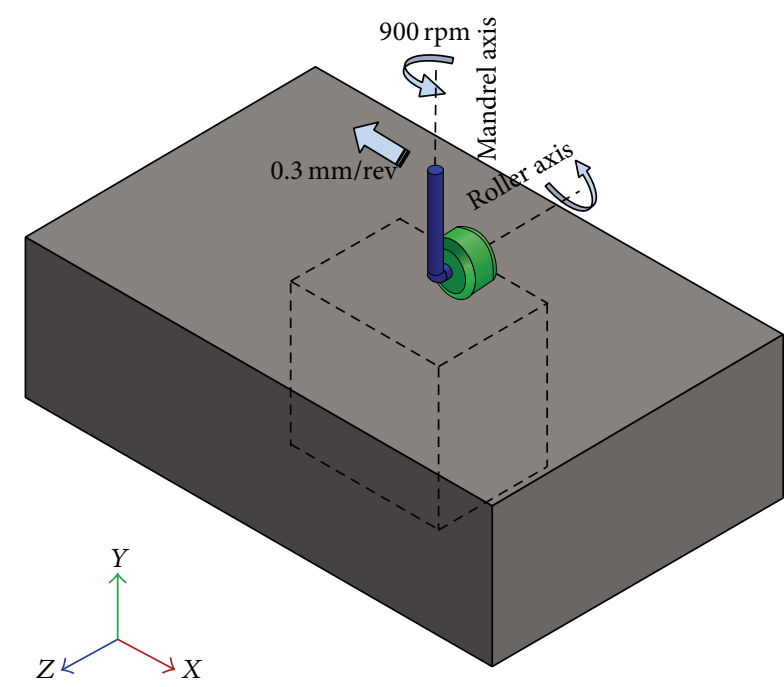

FIGURE 1: Schematic of deep rolling process on a relatively larger plate under complex roller path.

small translational speed. The motion of the roller is in such a way that the roller axis spins around the mandrel axis while the roller rotates around its axis. Figure 1 illustrates the schematic of deep rolling process under complex roller path. Such complex roller path cannot be simply represented by a two-dimensional model; therefore, a three-dimensional finite element model is proposed in this paper to better understand the reaction forces, contact stress distributions, deformation patterns, and residual stresses induced by this complex roller motion in the deep rolling process.

\section{Modeling Procedures}

As mentioned in the introduction, the main challenge in treating the deep rolling process is the multiplicity of paths that the roller involves. Thus, a holistic three-dimensional finite element model is proposed in the present paper. The model of deep rolling consists of a rigid mandrel, a rigid cylindrical roller, and a relatively larger elastic-plastic flat plate as shown in Figure 1. In order to simulate the process in an effective computational way, a finite domain (region within the dash lines in Figure 1) that contains regular continuum elements is specified. The infinite domain is arranged to surround the finite domain on four sides to represent relatively larger plate.

The multiple paths of the roller are depicted in Figure 2. The roller is free to spin around its own axis while the mandrel is rotating on the plate. The paths of the mandrel and roller are defined in the following steps.

(1) Initial Step. Initially, the roller is positioned on the starting point of the flat plate as shown in Figure 2(a). The initial condition of the plate is in a stress-free state at room temperature.

(2) Penetration Step. The mandrel rotates at a constant speed $N_{m}$ for one revolution without translational motion on the plate. During this revolution, the roller starts to spin around 


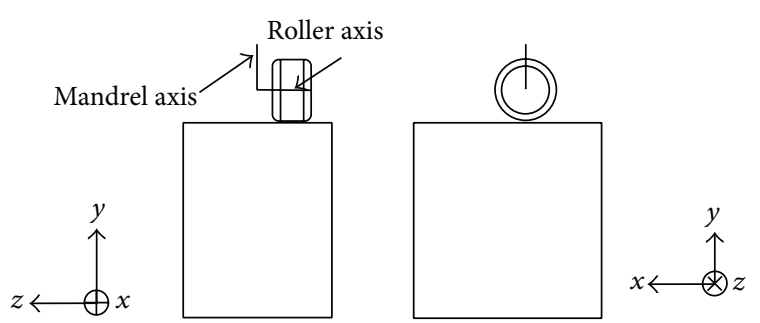

(a)

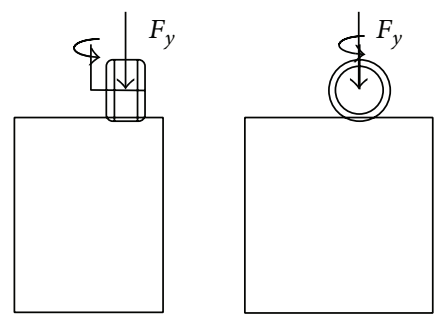

(b)
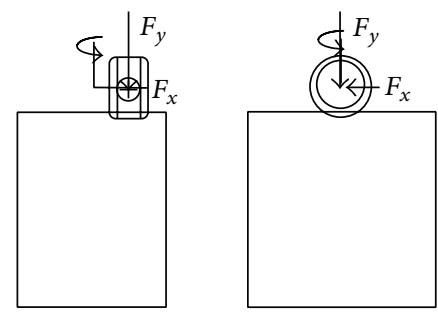

(c)
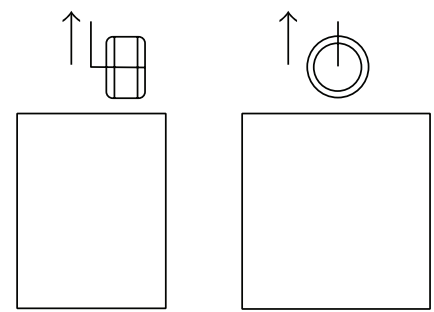

(d)

FIGURE 2: Multiple paths of the roller. (a) Initial step, (b) penetration step, (c) deep rolling step, and (d) recovery step with the left-hand column of plots being front views and the right-hand column of plots being right views.

the mandrel axis. Meanwhile, the roller is free to rotate around its own axis and linearly penetrates the flat plate at a constant speed $u_{r, y}$ so that the center of roller moves down to the full penetration $\delta$ at the end of the revolution as shown in Figure 2(b).

(3) Deep Rolling Step. The mandrel continues to rotate at the constant speed $N_{m}$ and in the same time the axis of mandrel moves on the plate with a constant small translational speed $u_{r, y}$. In this step, the roller continues to spin around the mandrel axis with the fixed penetration $\delta$. Figure 2(c) shows the deep rolling step.

(4) Releasing Step. The mandrel stops rotating and translating. The roller gradually moves up from the plate at a constant speed $u_{r, y}$.
(5) Recovery Step. The roller continues to move up to provide additional time for springback in the plate. The recovery step is shown in Figure 2(d).

The Cartesian coordinate system is used in the FE model. The selection of the sizes of the finite elements to simulate the multiple paths of roller motion follows the guidelines that are established in Ali and Pan [7] and will be reported in the next section according to the example. The bottom surface of the plate is constrained in the loading direction in all steps and this is the only constraint in the plate. The interaction behavior between the roller and the plate is modeled with Coulomb's law, taking 0.05 as the coefficient of friction for the highly lubricated rolling process $[11,14]$. The cooling function of lubricant and the free-to-roll configuration in the tool design allow for the assumption of isothermal deformation.

In addition to multiple paths of roller motion, an important factor that influences the deep rolling analysis is the material model. The material model, which can adequately represent the deformation response during loading and unloading, must account for strain hardening or softening during the process. Several models have been developed, with varying degrees of accuracy, to predict the deformation response of materials. Among these models, the JohnsonCook (JC) material model is the most widely used. The JC model has been proven to represent the plastic behavior of the material very well and has been extensively used to predict material behavior (flow) under high strain and strain rate as a function of the operating temperature. JC material model can be expressed as

$$
\sigma=\left(A+B \varepsilon^{n}\right)\left(1+C \ln \dot{\varepsilon}^{*}\right)\left[1-\left(T^{*}\right)^{m}\right],
$$

where $\sigma$ is the effective stress, $\varepsilon$ is the effective plastic strain, $\dot{\varepsilon}^{*}$ is the normalized effective plastic strain rate, $n$ is the work hardening exponent, and $T^{*}$ is the normalized temperature defined as

$$
T^{*}=\frac{T-T_{r}}{T_{m}-T_{r}},
$$

where $T, T_{m}$, and $T_{r}$ are the workpiece temperature, material melting, and room temperature, respectively. In (1), the first bracketed term represents the strain hardening of the yield stress, the next term models the increase in the yield stress at elevated strain rates, and the final bracketed term is a softening of the yield stress due to local thermal effects. Here, $A, B, C, n$, and $m$ are constitutive parameters fitted to the experimental flow stress data since the formulation of JC material model is empirically based. The model assumes that the strength is isotropic.

\section{Case Studies}

In this section, a deep rolling process that consists of a smooth cylindrical roller and a smooth relatively larger elastic-plastic flat plate will be used as an illustrative example. Simulation results for multiple paths of roller motion will be presented to

(1) demonstrate the effectiveness of the FE model in handling multiple paths in the deep rolling process, 
(2) highlight the difference between the proposed multiple paths model and the single indentation or single rolling ones,

(3) present the residual stress distributions in the nearsurface material after the material recovery vary along the roller path.

Three-dimensional FE analyses involving nonlinear material behavior and nonlinear boundary effects (contact and friction) typically resulted in very large models when the "implicit" technique was used. For this reason the "explicit dynamic" technique is prevalent in FE modeling works for the similar applications, especially in many manufacturing process modeling works, for example, Fu et al. [11], Klocke et al. [13], Mohammadi et al. [15], Sayahi et al. [12] for the burnishing process, Fischer and Schleinzer [16] for the straightening process, and Taylor et al. [17] for the sheet metal forming process. In the present paper, the FE analyses were implemented using the commercially available FE code ABAQUS with the explicit dynamic analysis technique and appropriate mass scaling [18]. Details about why the explicit technique and necessary "mass scaling," that is, added artificial mass, are widely used in manufacturing applications can be found in Klocke [19]. The cylindrical roller has a diameter of $4 \mathrm{~mm}$, a width of $2.5 \mathrm{~mm}$, and fillets of $0.5 \mathrm{~mm}$ on the two edges. The roller and mandrel are modeled as analytical rigid bodies since the roller and mandrel considered in the present paper have much higher hardness than the plate. The modeled finite-domain dimensions of elastic-plastic plate are $12 \times 9.5 \times 12.5 \mathrm{~mm}$. These dimensions are used to avoid boundary/edge effects while providing enough dimensions for establishing elastic-plastic deformation in an effective computational manner. In order to represent a relatively larger flat plate, semi-infinite elements on the four sides are employed and extrusion cuts are arranged on the four corners to accommodate the semi-infinite elements.

Figure 3 illustrates the 3D finite element mesh for deep rolling in the Cartesian coordinate (throughout this paper, the Cartesian coordinate notations $x, y$, and $z$ and 1,2 , and 3 will be used interchangeably for convenience). Eight-node linear brick elements with reduced integration and hourglass control (C3D8R) were used in the finite domain and eightnode linear semi-infinite brick elements (CIN3D8) were used along the four sides. Since the semi-infinite elements provide boundary conditions by their nature, the only boundary condition utilized in the model was the constraint of plate bottom area. The fine meshes of $20 \times 20 \times 21 \mu \mathrm{m}$ (compared to the mesh size of $50 \mu \mathrm{m}$ for a 6 -mm diameter ball in [13]) were used in the contact interactive area while coarse meshes of $250 \times 136 \times 207 \mu \mathrm{m}$ were used in the field far away from the rolling contact so that the contact stress distribution was modeled accurately and efficiently. In total, 4,625,964 nodes and 4,386,760 elements were used for the elasticplastic deformable plate. The complex roller paths are given as $N_{m}=900 \mathrm{rpm}$ for the constant mandrel rotational speed, $\delta=40 \mu \mathrm{m}$ for the penetration step, and $u_{m, x}=0.3 \mathrm{~mm} / \mathrm{rev}$ for the deep rolling step. The corresponding $u_{r, y}$ can be found as $0.6 \mathrm{~mm} / \mathrm{s}$.

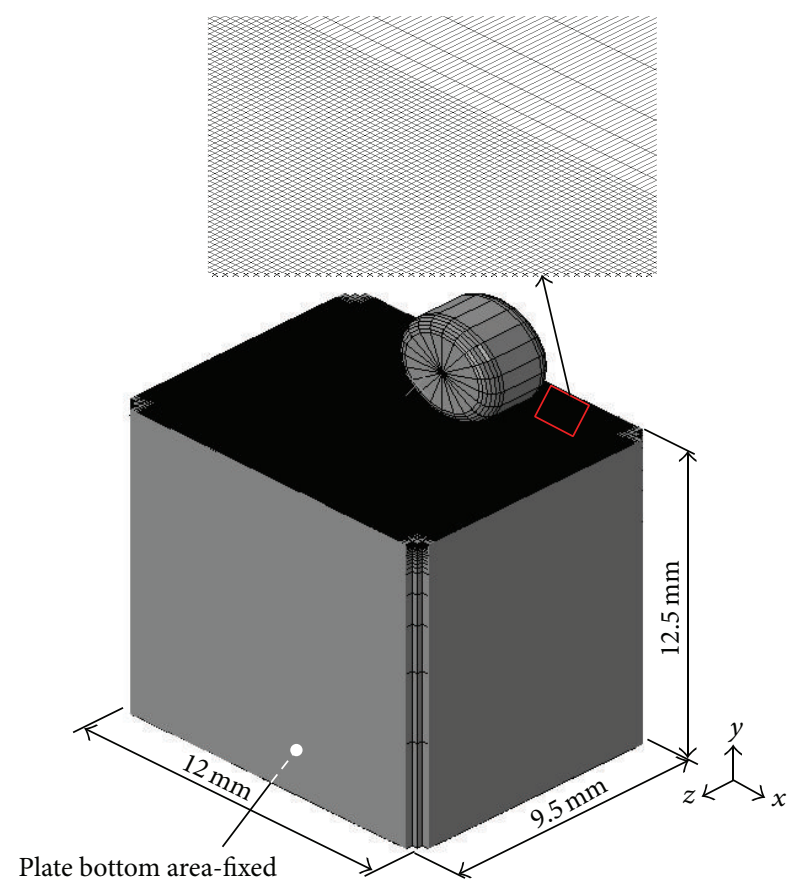

FIGURE 3: Three-dimensional finite element mesh of deep rolling.

TABLE 1: Material properties of Ti-6Al-4V, $[1,20]$.

\begin{tabular}{lc}
\hline Density & $4430 \mathrm{~kg} / \mathrm{m}^{3}$ \\
Young's modulus & $110 \mathrm{GPa}$ \\
Poisson's ratio & 0.342 \\
\hline
\end{tabular}

TABle 2: Parameters of Johnson-Cook material model for Ti-6Al$4 \mathrm{~V}[20]$.

\begin{tabular}{lc}
\hline Yield strength, $A$ & $968 \mathrm{MPa}$ \\
Strain hardening coefficient, $B$ & $380 \mathrm{MPa}$ \\
Strain rate coefficient, $C$ & 0.0197 \\
Strain hardening exponent, $n$ & 0.421 \\
Thermal softening exponent, $m$ & 0.577 \\
Melting point, $T_{m}$ & $1605^{\circ} \mathrm{C}$ \\
\hline
\end{tabular}

The material constitutive constants for the JC model have been introduced into the finite element code in ABAQUS. The elastic-plastic flat plate considered in the present paper is $\mathrm{Ti}$ 6Al-4V alloy. This alloy offers a combination of high strength, light weight, formability and corrosion resistance which have made it a world standard in various applications such as aerospace, automotive, and marine equipment. The material properties of Ti-6Al-4V are listed in Table 1 . The parameters of JC material for Ti-6Al-4V are shown in Table 2. These data are obtained from modified split Hopkinson pressure bar (SHPB) tests at strain rate up to $10^{3} \mathrm{~s}^{-1}$ and temperature up to $600^{\circ} \mathrm{C}$ [20]. Figure 4 shows the stress-strain curve of Ti-6Al$4 \mathrm{~V}$ from the JC material model at room temperature.

The FE model has been validated through two ways. First, in an elastic contact condition-that is, the boundary conditions, element type, and mesh size-by comparison 


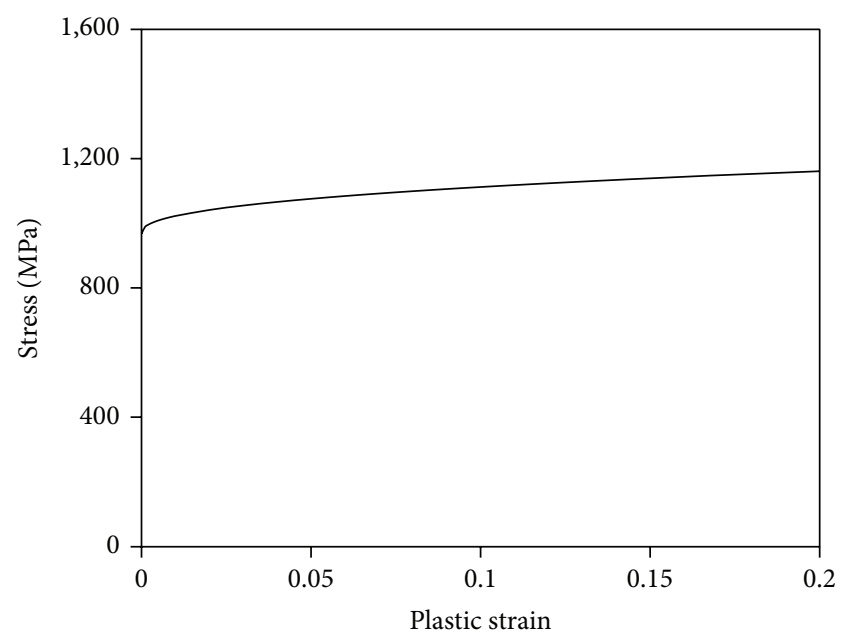

FIGURE 4: Stress-strain curve of Ti-6Al-4V from J-C model predictions at room temperature.

with the analytical solution of Hertzian line contact for an indentation simulation between the cylinder and flat plate surface when the contact is still in the elastic deformation stage, that is, for very low loads. The difference between the Hertz theory and the FE model for the contact band width, pressure, and von Mises stress was found to be smaller than $5 \%$. The difference between the FE and analytical solution in the elastic deformation stage can be explained by the boundary conditions of the FE model that differ slightly from the half-space assumption in Hertz theory. Second, in a simple loading path of deep rolling process, details are shown in the Appendix of the present paper.

Figures 5(a) and 5(b), respectively, provide the complex paths of the reference point on the rigid mandrel for the complex roller path in the deep rolling process. In the penetration step, 0 through 0.07 seconds, $U 2$ linearly reduces with time while UR2 linearly increases with time. In the deep rolling step, 0.07 through 0.2 seconds, $U 1$ linearly declines with time due to the negative small translational displacement and UR2 continuously increases over the time. In the releasing step, 0.2 through 0.27 seconds, and the material recovery step, 0.27 through 0.3 seconds, only $U 2$ increases with time. Note that $U 3, U R 1$, and $U R 3$ are not plotted in Figure 5 since they remained zero in all time.

As mentioned previously in this section, an appropriate mass scaling has to be employed in the present $\mathrm{FE}$ analysis to enable a time-efficient simulation of the process. The appropriateness of mass scaling means that the artificial mass is added to the system without adulterating the global solution. One way to check the appropriateness of mass scaling is to compare the kinetic energy to the internal energy. Figure 6 shows the model kinetic energy and internal energy as a function of time, revealing the appropriateness of mass scaling.

Figure 7 shows the reaction forces with respect to the reference point on the mandrel. The magnitude of reaction force in the penetration direction, RF2, is the most significant

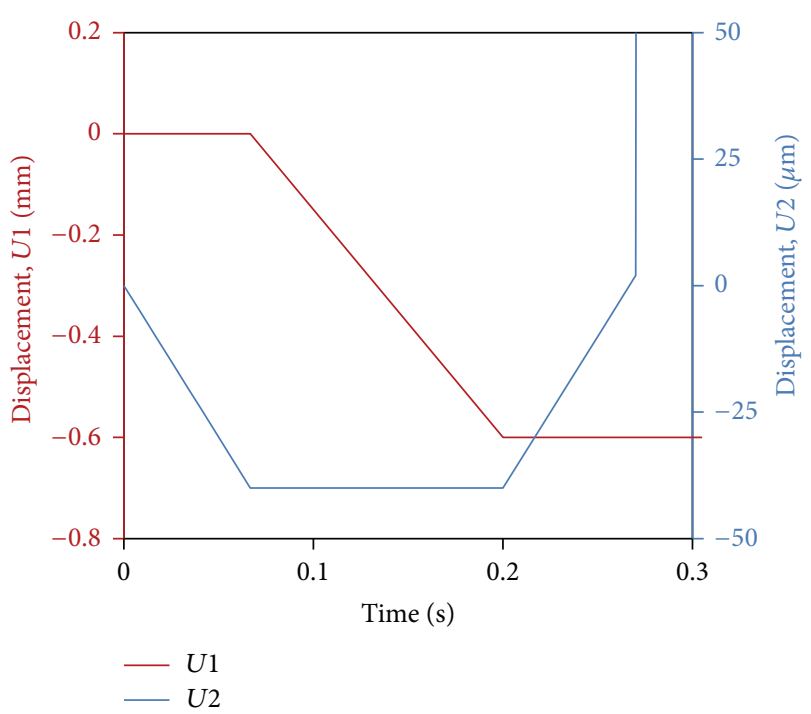

(a)

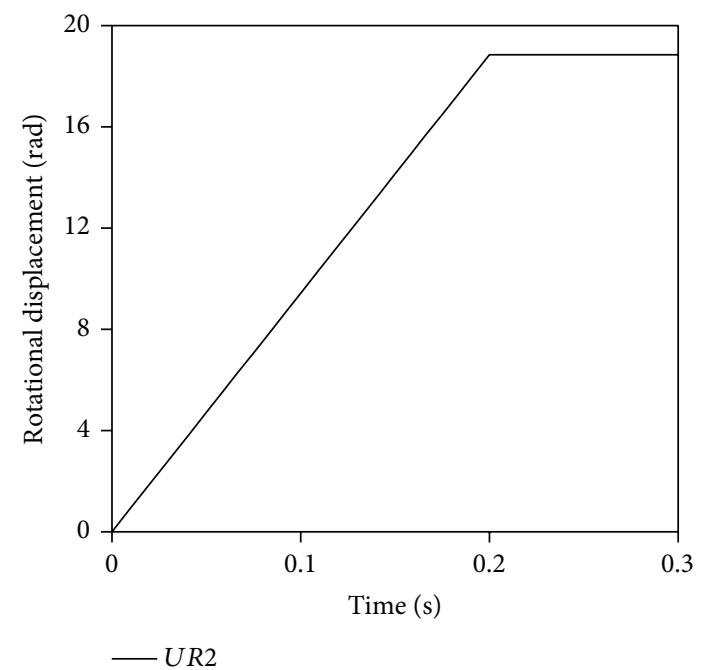

(b)

FIGURE 5: Displacements of the reference point on the rigid roller for the complex roller path in the deep rolling process. (a) Translational and (b) rotational.

one, which reaches the peak $(-3291 \mathrm{~N})$ at the end of penetration step. The magnitude of RF2 starts to decrease with time when the roller motion changes to the deep rolling step. The reduction of RF2 can be explained by Figure 8, which shows the historical displacement $U 2$ of a point located on the plate upper surface within the rolling track and in the contact bandwidth near the end of revolution. This point is pushed down $40 \mu \mathrm{m}$ then quickly recovers $22 \mu \mathrm{m}$ after the roller passes the point. The near-surface material is workhardened in this step. However, when the roller comes to pass the same point, the roller only needs to penetrate $22 \mu \mathrm{m}$ instead of $40 \mu \mathrm{m}$. As a result, the RF2 magnitude is reduced. It can also be seen in Figure 6 that, with the specified roller displacement of $40 \mu \mathrm{m}$, the near-surface material reaches its saturated stress state after two or three times of deep rolls. The residual strain will no longer increase if no higher force 


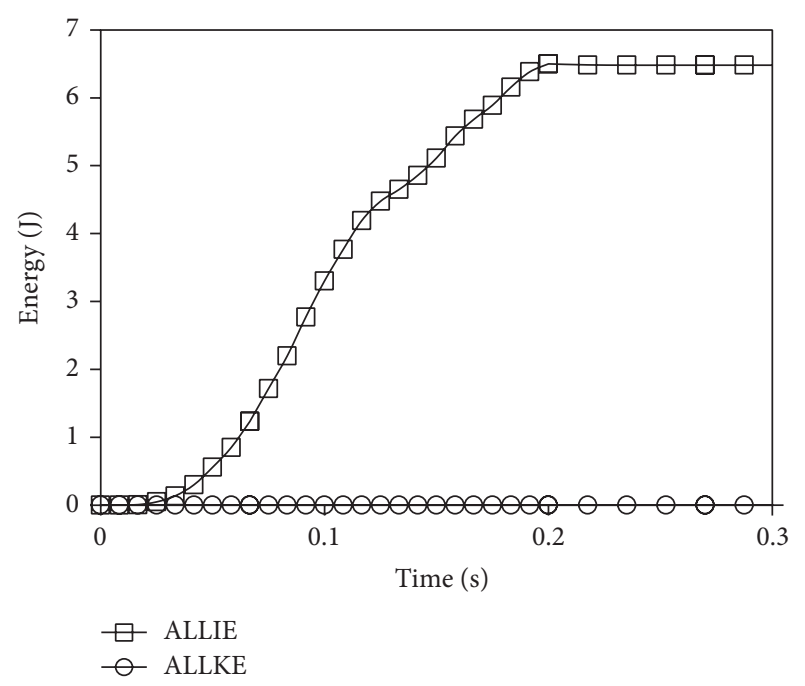

FIgURE 6: Model internal energy (ALLIE) and kinematic energy (ALLKE), showing insignificant inertia effects.

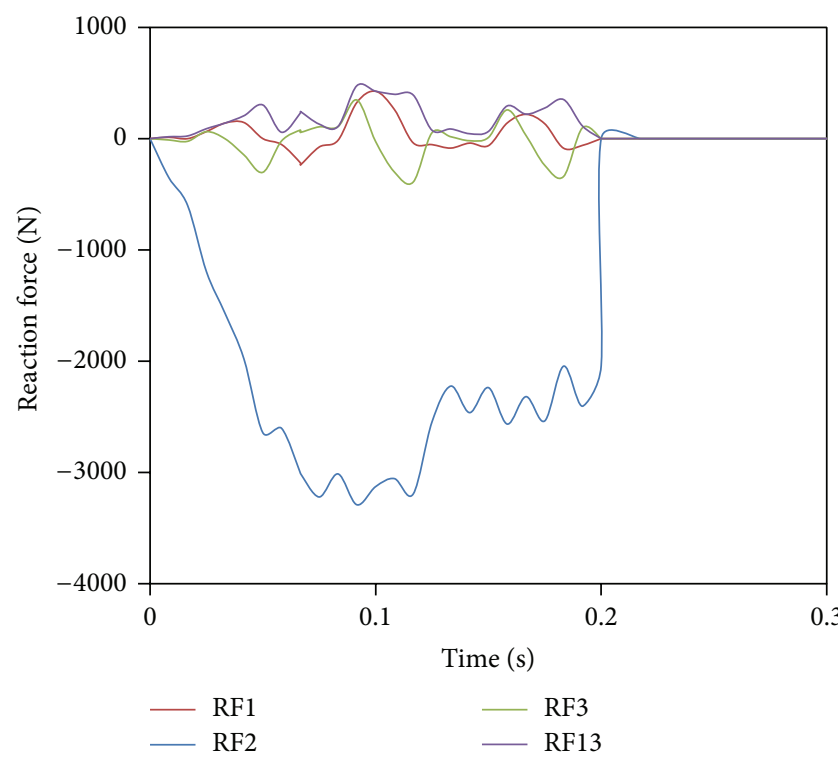

FIGURE 7: Reaction forces of the roller for the complex roller path in the deep rolling process.

or deeper roller displacement is specified in the later rolling path.

Figure 7 also shows that the magnitude of resultant reaction force (RF13) on the plate surface is approximately $10 \%$ of RF2. This indicates that the deep rolling process at the prescribed roller displacement and motion requires 5\% of RF2 to overcome the material in front of the roller leading edge in addition to the $5 \%$ of RF2 for the interfacial frictional resistance. In the perspective of machine tool design, the magnitude of RF13 is most likely not a concern to the tool holder.

Figures 9(a), 9(b), 9(c), and 9(d), respectively, show the Mises stress distributions as the mandrel rotates 0.5-, 1.5-, 2.5revolution, and at the end of material recovery step. Here,

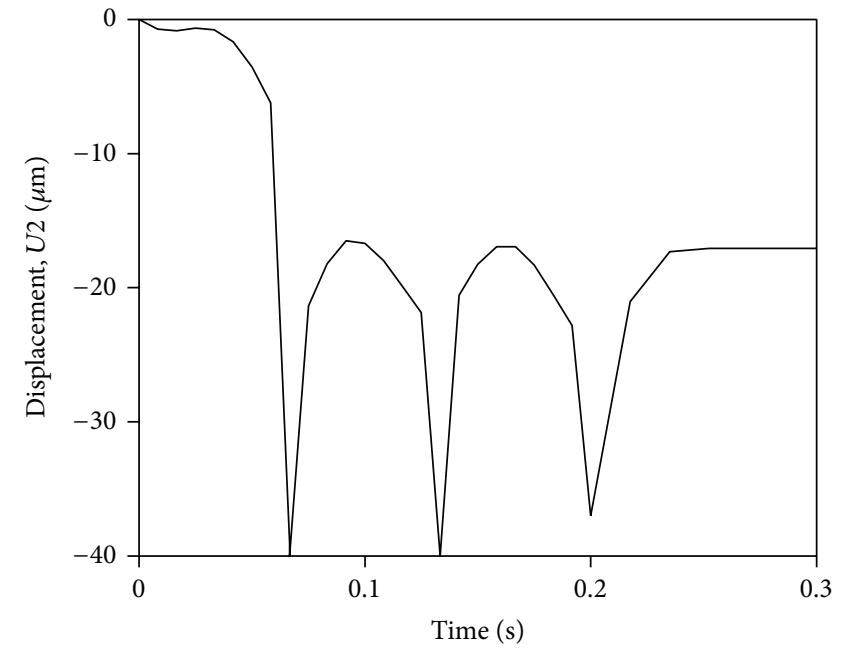

FIGURE 8: The historical displacement component $U 2$ of a point on the plate upper surface within the rolling track and in the contact bandwidth near the end of revolution.

the left-hand and right-hand figures represent the top- and cut-view, respectively. Note that the roller is removed from these figures in order to see the stress distribution completely. Figure 9(a) clearly shows that the roller gradually pushes down and the material yielding has been faded in along the roller path. In the cut-view of Figure 9(a), the orange and red areas on the $y-z$ plane are the material that is yielded and hence this area represents the plastic zone size and shape. At this instance, the maximum depth of equivalent plastic strain (PEEQ) zone is approximately $726 \mu \mathrm{m}$, including $20 \mu \mathrm{m}$ of roller displacement. In the cut-view of Figures $9(\mathrm{~b})$ and $9(\mathrm{c})$, the maximum depth of PEEQ zone on the $y-z$ plane at both instances increases to $1210 \mu \mathrm{m}$, including $40 \mu \mathrm{m}$ of roller displacement. At the end of material recovery step, the maximum depth of PEEQ zone on the $y-z$ plane reduces to $260 \mu \mathrm{m}$.

It is interesting to compare the Mises contour shape in the plastic zone. Figure 10 shows such contours with a cutoff of minimum stress limit at $862 \mathrm{MPa}$ on the $y-z$ plane below the contacts as the roller spins 0.5-, 1.5-, and 2.5-revolution. The Mises contour shape has been changed from a symmetric form to an asymmetric form as the step changes from the penetration step to the deep rolling step.

Figure 11 shows the contact pressure profiles along the center of rolling track when the roller rotates 0.5-, 1.5-, and 2.5-revolution. These profiles indicate that the contact pressure distribution is no longer in semi-ellipsoidal shape or Hertzian pressure distribution when the plate is in the elastic-plastic deformation. The maximum contact pressure occurs at the leading edge of the roller instead of the contact center. This is due to the unpenetrated material in front of the roller, forming an obstacle to the roll motion. Similar contact pressure profiles can also be found in Ali and Pan [7] by using an elastic-plastic power-law strain hardening material with a nonlinear kinematic hardening rule. In the present paper, the peak pressures are 3.3,3.7, and $4.0 \mathrm{GPa}$ when 

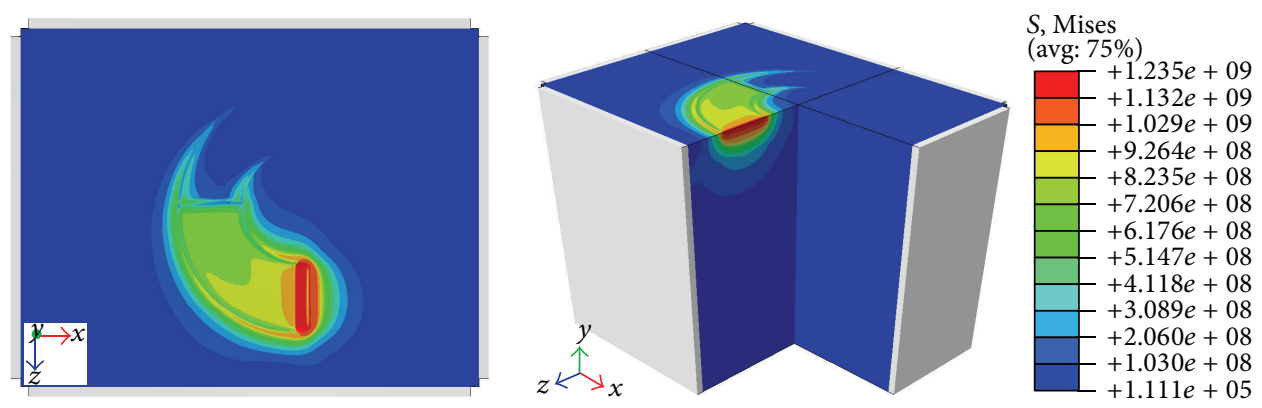

(a)
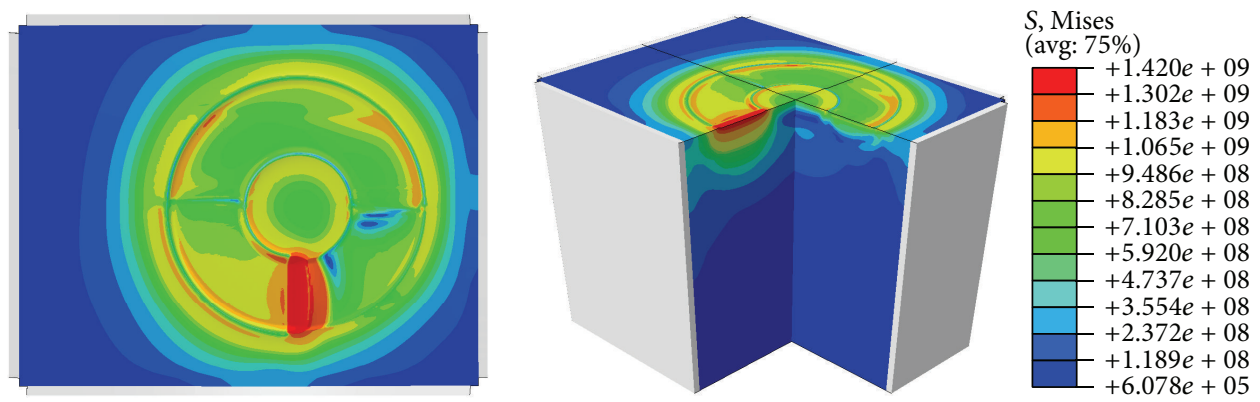

(b)
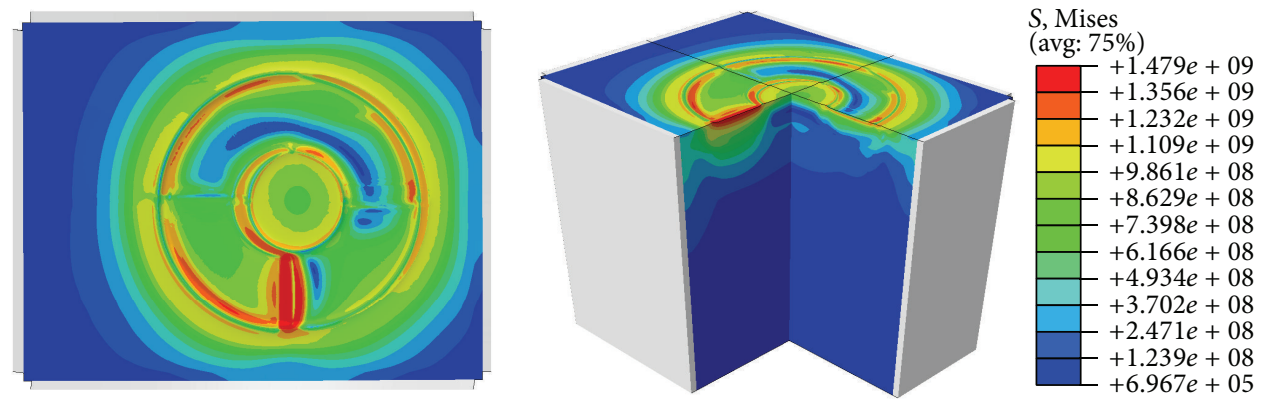

(c)
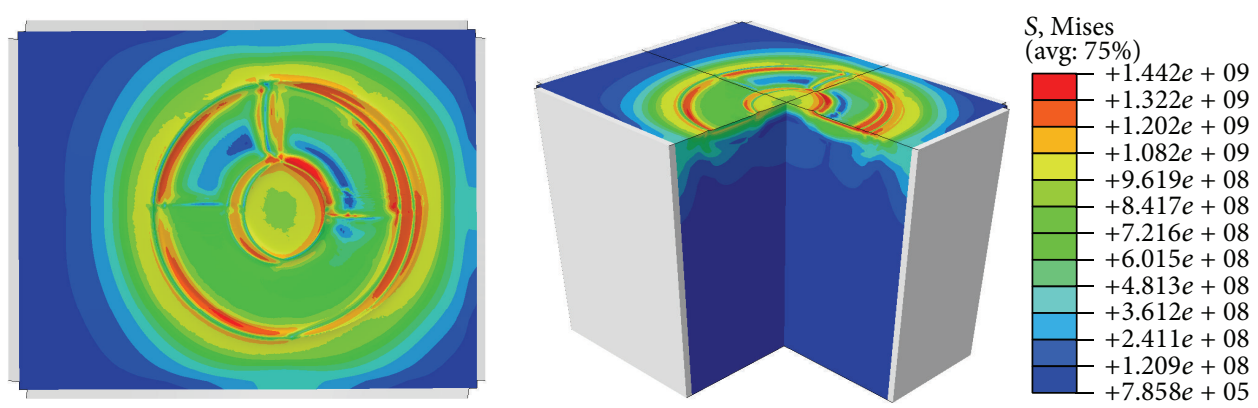

(d)

FIGURE 9: Mises stress distributions on the plate upper surface (top-view in the left-hand column) and in the plate (cut-view in the right-hand column) when the roller spins (a) 0.5-revolution, (b) 1.5-revolution, (c) 2.5-revolution, and (d) the roller is at the end of recovery step. Note that the roller is removed from the figure in order to see the stress distribution completely and all units are in Pa.

the roller rotates $0.5-, 1.5-$, and 2.5-revolution, respectively. The corresponding contact widths are $0.452,0.819$, and $0.530 \mathrm{~mm}$ for these roller locations. The results reflect the complexity of material penetration and strain-hardening in this present paper. For example, at 0.5 -revolution, the plate is penetrated approximately $20 \mu \mathrm{m}$. At 1.5-revolution, the plate is approximately penetrated $35 \mu \mathrm{m}$ and in the same time the material that the roller contacts with has been strainhardened; therefore, a higher peak pressure and wider contact width are expected. At 2.5-revolution, although the roller penetrates only $23 \mu \mathrm{m}$ of material, the material has much higher strain-hardening compared to that at 1.5-revolution; 


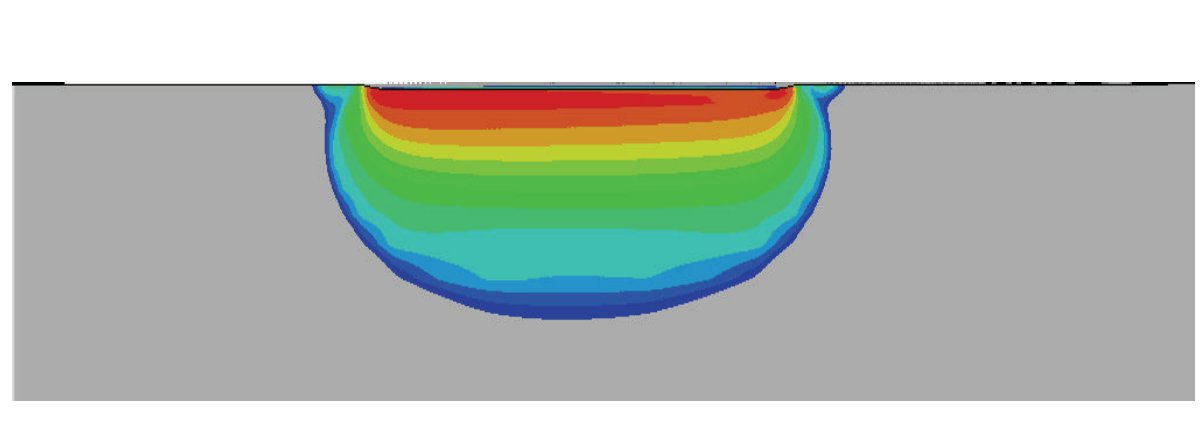

$S$, Mises (avg. 75\%)

\section{(avg: $75 \%)$}

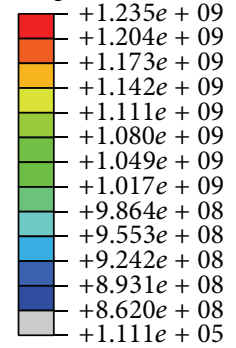

(a)

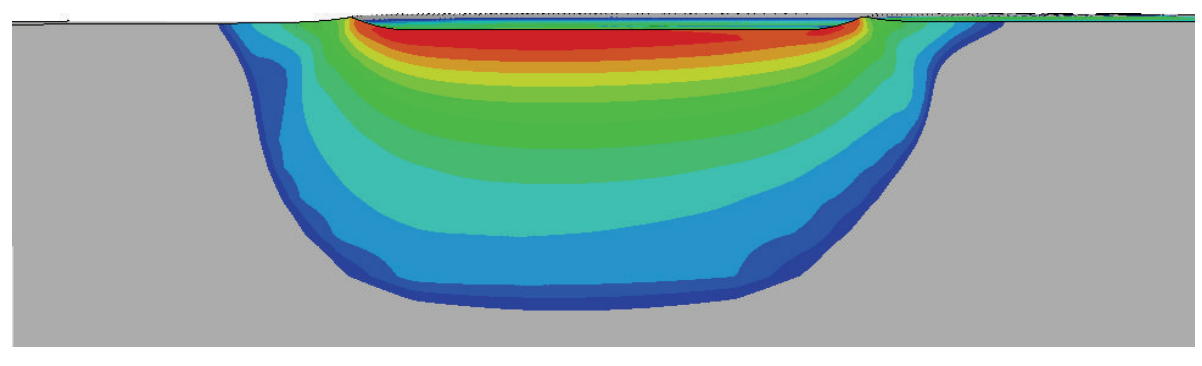

$S$, Mises (avg: 75\%)

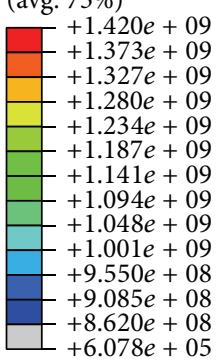

(b)

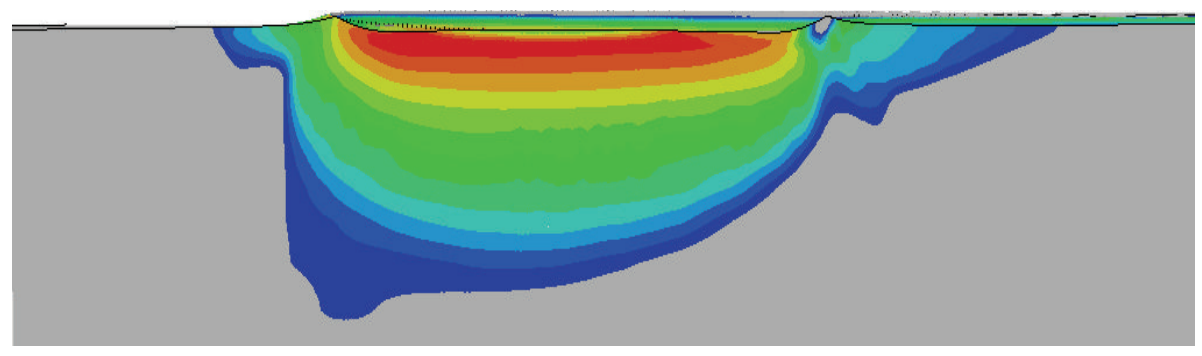

$S$, Mises

(avg: 75\%)

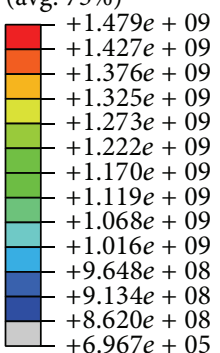

(c)

Figure 10: Mises contours with a cutoff of minimum stress limit at $862 \mathrm{MPa}$, the yield strength of Ti-6Al-4V on the $y-z$ plane below the contacts as the roller spins (a) 0.5-revolution, (b) 1.5-revolution, and (c) 2.5-revolution. All units are in Pa.

hence, a higher peak pressure is generated but narrower contact width between the roller and the plate.

Figure 12 shows a comparison of the residual stresses distributions starting from the plate top surface when the roller is at the end of recovery step. Note that the residual stresses diminish as the depth increases from the plate top surface. In order to clearly show the residual stress profiles in the near-surface material, only the residual stresses within $2 \mathrm{~mm}$ depth are depicted. Four spots on the plate top surfaces are selected to review the residual stress distributions: 12, 9, 6, and 3 o'clock positions. These positions are corresponding to the 0-, 0.25-, 0.5-, and 0.75-revolution of the roller around the mandrel axis, respectively. These positions are located within the deep rolling track. It can be obviously seen in Figure 12 that the complex roller path induces compressive residual stress into the near-surface of the material. Residual stress components $S 11$ and S33, which align with the two orthogonal directions of the deep-rolling plane, are considerable while the other four components, S22, S12, S13, and S23, are relatively insignificant and can be considered negligible.

In Figure 12, the maximum magnitudes of $S 11$ and S33 range approximately from 900 to $1,500 \mathrm{MPa}$ and the induced compressive residual stresses $S 11$ and $S 33$ are about $1 \mathrm{~mm}$ deep. Figure 11 shows the $S 11$ and $S 33$ contours of residual stress on the plate top surface. It can be seen from Figure 13 that the residual stress distributions within the deep rolling track are not uniform. It is also found from Figure 13 that $S 11$ in the regions near the outer boundary of the roller track and near 12 and 6 o'clock positions drastically turns into tensile stress when approaching the surface. Similar conditions also occur for S33 in the regions near the outer boundary of the roller track and near 9 and 3 oclock positions. Some regions near the inner boundary of the roller track also have tensile stress on the surface.

There is little information available in the literature regarding these tensile residual stresses near the inner and 


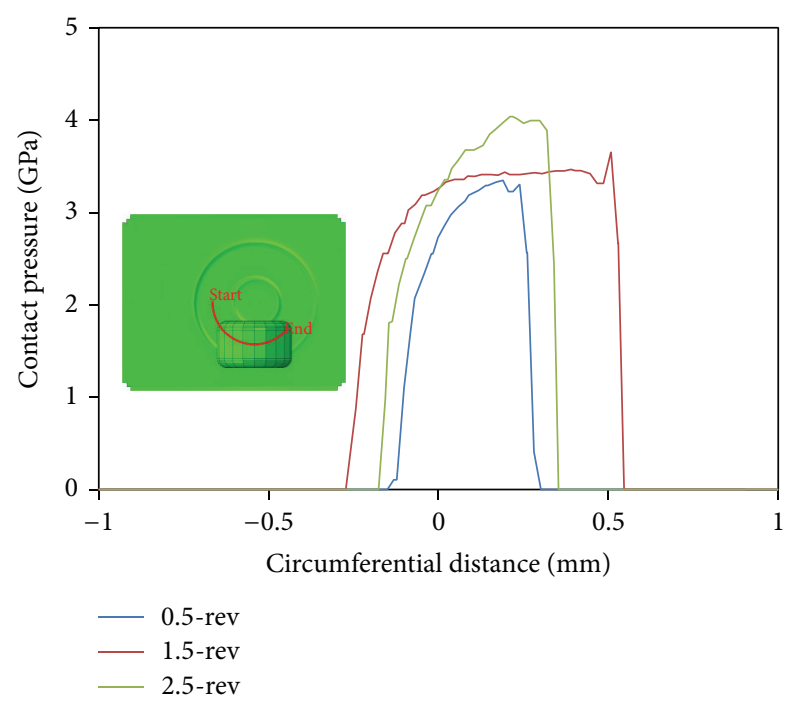

FIGURE 11: Contact pressure distributions at different steps.

outer boundaries of the roller track since most of the deep rolling processes are simulated by using simplified $2 \mathrm{D}$ models. However, the authors in the present paper find that these positive stress regions could be generated by the combination of microslip and small translational motion of roller for the complex roller paths specified in the present paper. The microslip phenomenon was first observed by Heathcote [21] in 1921 for a ball rolling in a groove. When a ball is rolling in a groove with a cross-sectional radius of curvature close to that of the ball itself, the contact area is no longer planar but shares the transverse curvature of the ball and groove; surface points in different transverse positions on the ball have different peripheral speeds which lead to microslip. More details about the Heathcote microslip can be found in Johnson [22]. In the present paper, the roller has rounded fillets of $0.5 \mathrm{~mm}$ on the two edges. When the roller is in the deep rolling step, the rolling track boundaries and the edges of the roller have very close conformity, this can lead to the microslip on the interface near the edges of the roller. The small translational motion in the deep rolling step also contributes an offset effect so that the high tensile stresses of $S 11$ do not occur exactly at the 12 and 6 oclock positions but offset toward the 11 and 5 o'clock positions. Similarly, the high tensile stresses of $S 33$ offset a little bit further from the 3 and 9 oclock positions.

Although the tensile stress appears in some regions in the roller track, the authors find that the neighboring surfaces surrounding the inner and outer track boundaries tend to have significant compressive stress levels, especially in $S 11$ that aligns with the mandrel translational direction. Residual stress profiles for a depth path near the outer track at the 3 o'clock position as shown in Figure 12(e) is plotted in Figure 14. This figure shows that residual stress distributions out of the deep rolling track can be different. A strip or a band with significant compress residual stress is expected to form if the deep rolling continues this complex path further to the left side of the plate top shown in Figure 12(e).

\section{Comparison to Published Experimental Studies of Deep Rolling under Simple Roller Path Using a Ball Tool}

So far, there is no documented experimental result using a cylindrical roller under complex roller path. There are, however, limited numbers of well-documented experimental studies available in the literature for the deep rolling process under simple roller path using a ball tool with limited normal load due to the usage of hydraulic pressure system. All of the experimental measurements used the ball tools to deep roll the specimen on a bar-stock or plate structure. Among these experimental measurements, Nalla et al. [1] and Tsuji et al. [23] used the ball tool to deep roll Ti-6Al-4V alloy bars around the circumferential direction. Residual stresses induced by the deep rolling like process under simple roller path in $[1,23]$ were measured using X-ray diffraction method. In Figure 15, the predicted residual stress $S 11$ from Figure 14 for the penetration-controlled deep rolling process using cylindrical roller under complex roller path are compared to the measurements of Nalla et al. [1] and Tsuji et al. [23] under simple roller path. Note that the residual stress profiles from experiments $[1,23]$ are in the axial direction of bar-stock specimen. The experimental results available in $[1,23]$ are used here to illustrate the benefit of using high depth of penetration deep rolling process to achieve higher compressive residual stress in comparison with the limited normal loading system. It is observed that (i) the predicted S11 on the surface and in the near-surface material for the complex roller path using a cylindrical tool has significant higher compressive residual stress than those obtained from experiments $[1,23]$ for the simple roller path using a ball tool, (ii) both the predicted and measured maximum compressive residual stress from experiments [1,23] occur in the depth of 0.02 to $0.07 \mathrm{~mm}$ from the surface, (iii) the predicted $S 11$ and measured residual stresses from experiments $[1,23]$ are in the same range at $0.5 \mathrm{~mm}$ below the surface, and (iv) the compressive residual stress affected depth is approximately in the same range of $0.6 \mathrm{~mm}$ for the model predictions and measurements from experiments $[1,23]$.

It should be noted that Figure 15 has been extracted for a comparison of residual stress on the surface, at their maximum values and at $500 \mu \mathrm{m}$ below the surface in the absence of exact and direct experimental measurements of deep rolling process under complex roller path using a cylindrical tool. However, as more closed experimental data of complex roller path becomes available it may be incorporated readily into a quantitative comparison and model validation.

\section{Conclusions}

A comprehensive 3D finite element dynamic analysis with considering a complex roller path is conducted to simulate the deep rolling process. In this analysis, the roller is modeled as a rigid body and is in contact with a relatively larger plate under highly lubricated condition. The plate material is modeled as an elastic-plastic material by using the JC material 


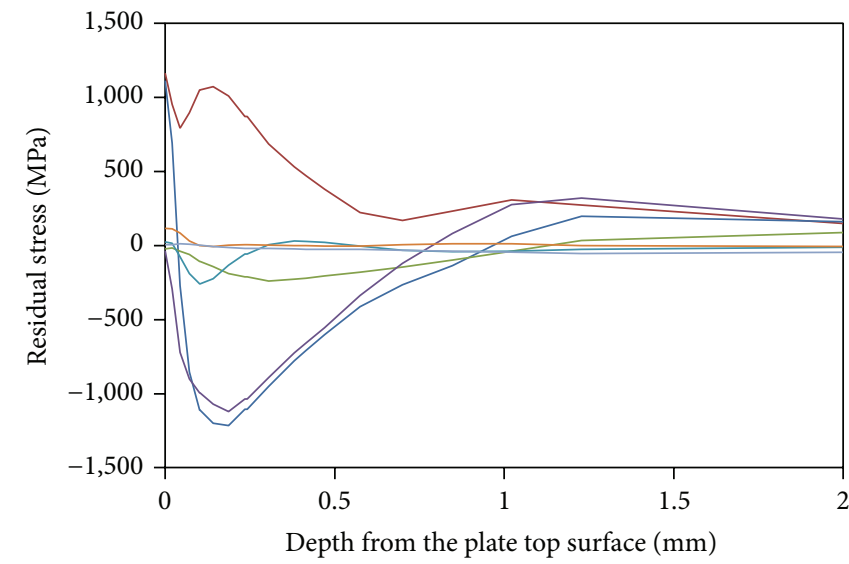

(a)

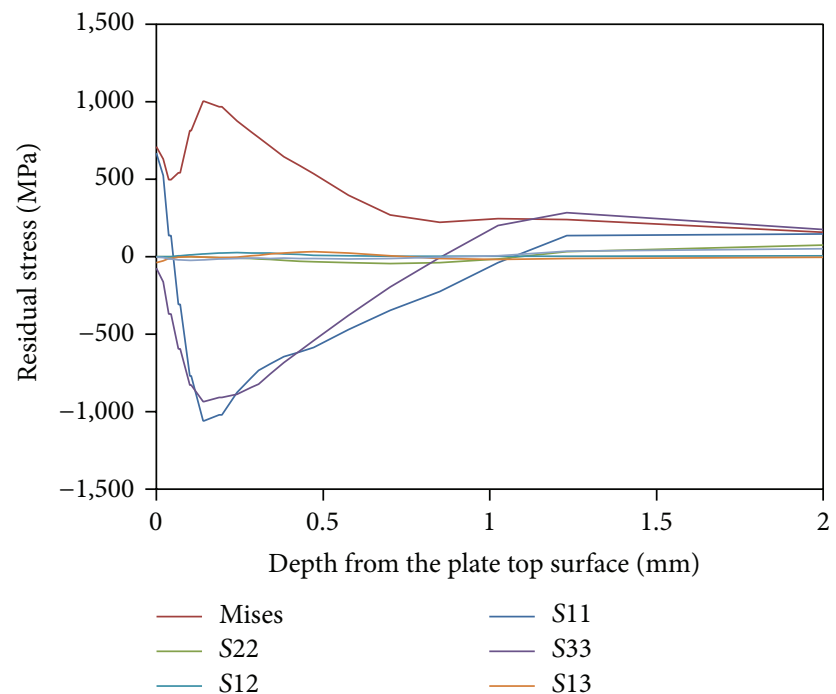

(c)

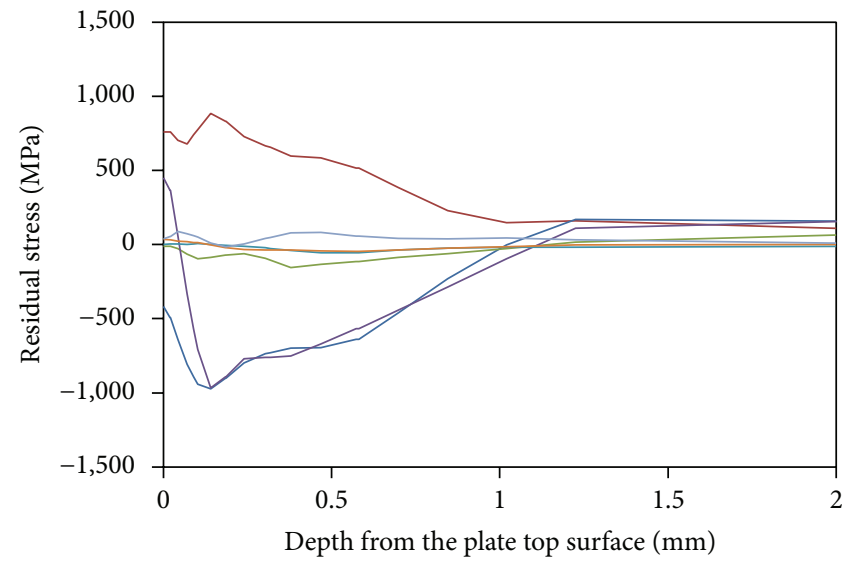

(b)

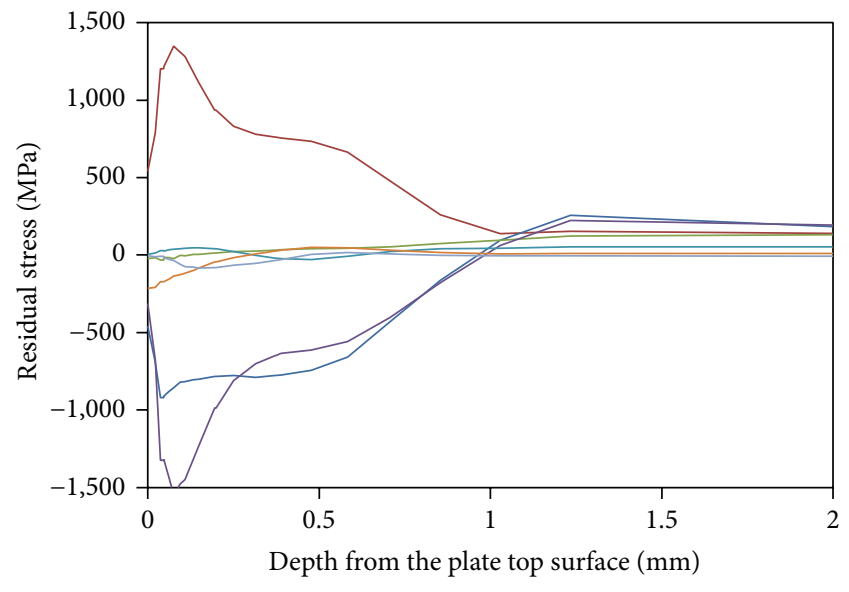

(d)

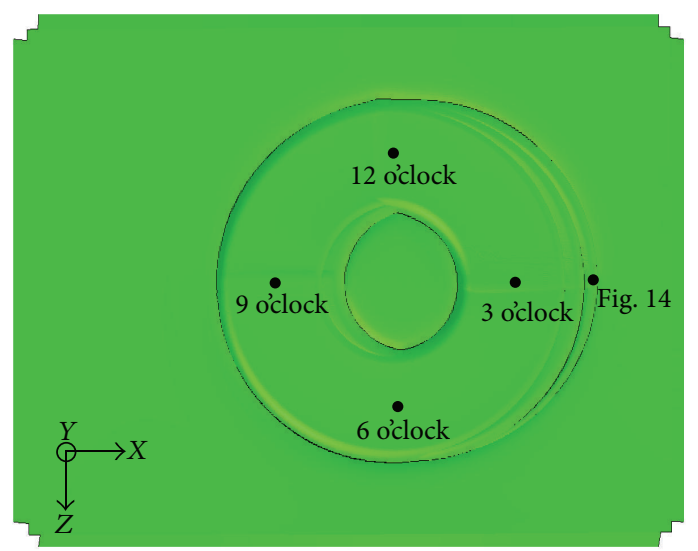

(e)

FIGURE 12: Residual stress distributions within the rolling track at (a) 12 o'clock, (b) 9 o'clock, (c) 6 o'clock, (d) 3 o'clock position when the roller is at the end of recovery step, and (e) the positions for paths of residual stress. 


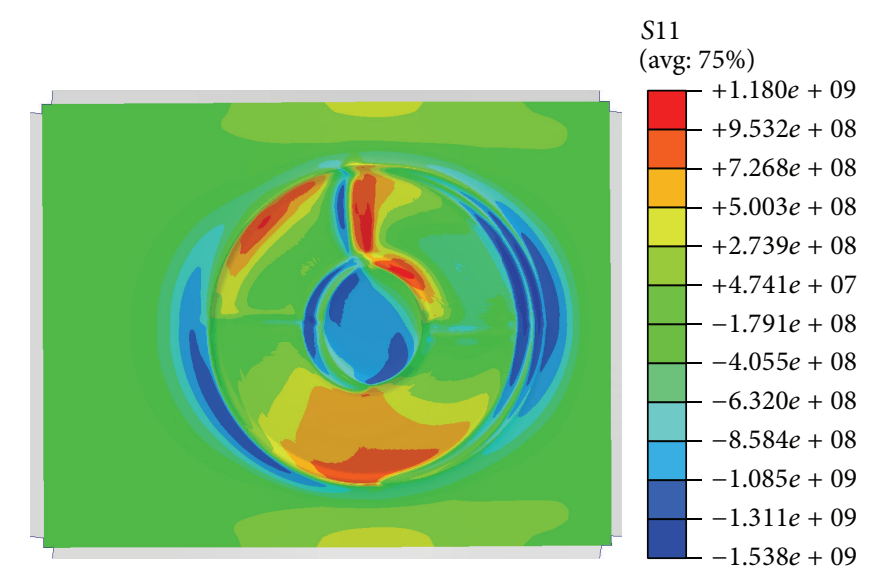

(a)

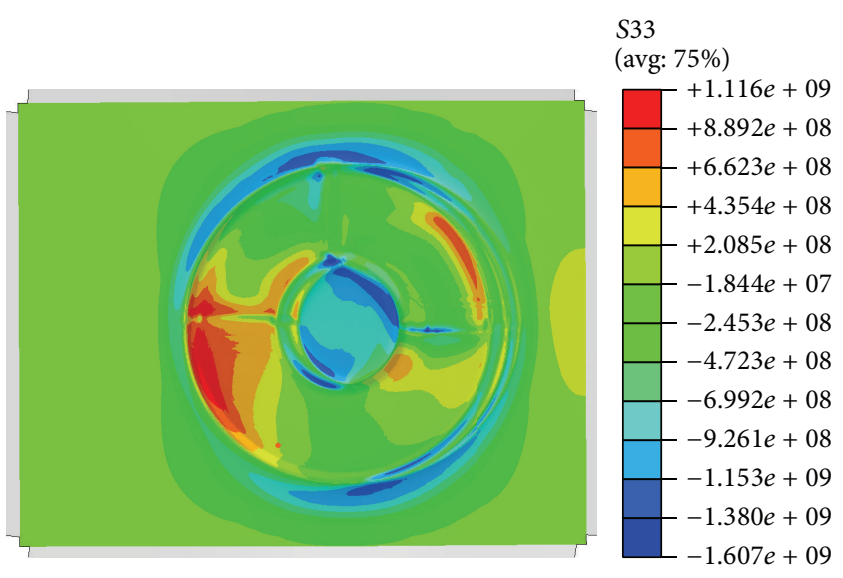

(b)

FIGURE 13: Contours of residual stress on the plate top surface at the end of recovery step: (a) S11 and (b) S33. All units are in Pa.

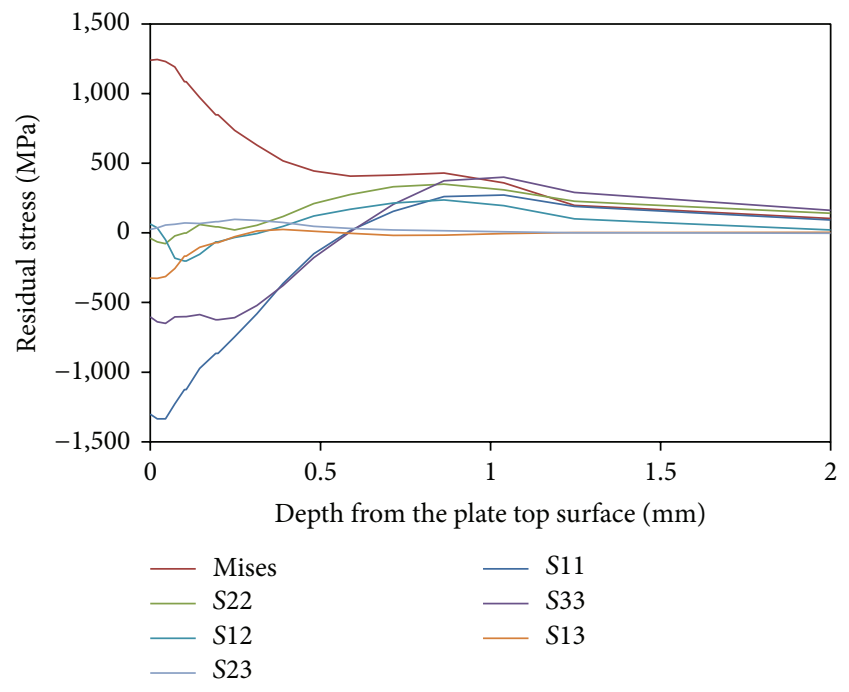

FIGURE 14: Residual stress distributions in the material neighboring the outer track at the 3 oclock position shown in Figure 12(e).

model for the strain hardening and deformation response in the process. The results can be summarized as follows.

(1) The magnitude of resultant resistant force on the plate surface is approximately $10 \%$ of the loading force, which consists of $5 \%$ of the loading force on the prescribed interfacial friction and $5 \%$ of loading force on the material penetration in front of the roller. This helps a designer in implementing the high speed spindle tool design.

(2) The magnitude of loading force in the penetration direction (depth direction) starts to decrease with time when the roller path changes to the deep rolling step and the residual stress distributions in the nearsurface material after the material recovery step vary along the roller path.

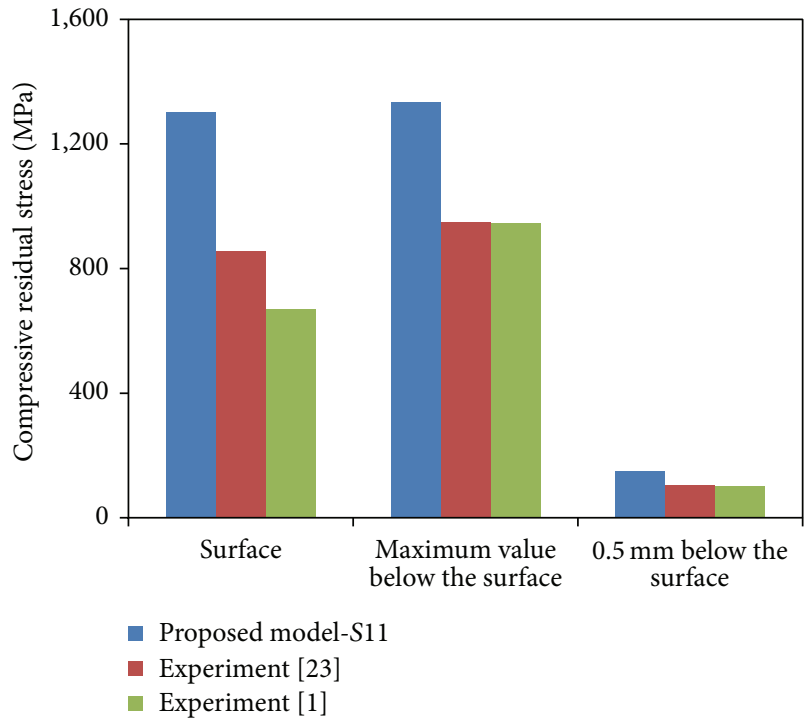

FIGURE 15: Comparison of the predicted residual stress $S 11$ from Figure 14 for the complex roller path to the measured residual stresses from $[1,23]$ for the simple roller path.

(3) With a specified roller displacement, the subsurface material reaches its saturated stress state after two or three times of deep rolls. The residual strain will not increase if no deeper roller displacement is performed.

(4) The contact pressure distributions are no longer in semiellipsoidal shape or elastic Hertzian pressure distribution when the plate is in the deep rolling process.

(5) The residual stress components $S 11$ and $S 33$ in the near-surface material within the deep rolling track are greater than the other components. The peak values of compressive $S 11$ and $S 33$ are in the range between 900 and $1,500 \mathrm{MPa}$ for the proposed complex roller path in the deep rolling process. 


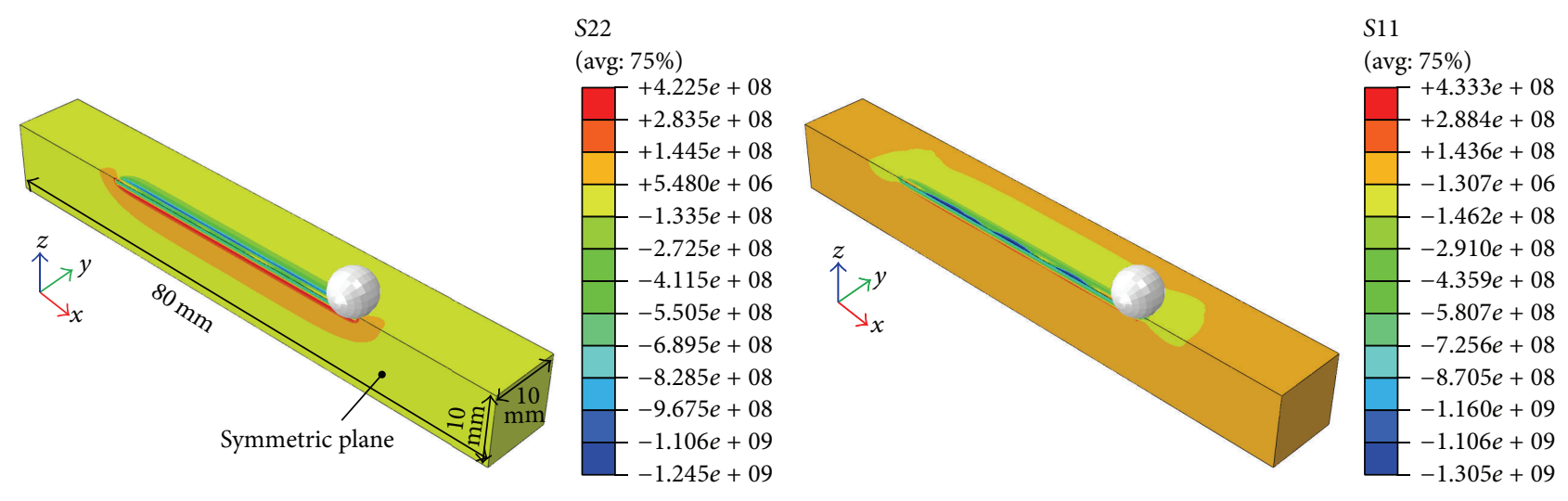

FIGURE 16: Predicted distribution of residual stresses $S 11$ and $S 22$ for the simple roller path. All units are in Pa.

(6) The residual stress components $S 11$ and $S 33$ on the deep rolled surface vary with the roller path. $S 11$ near 12 and 6 o'clock positions and S33 near 9 and 3 o'clock positions drastically turned into tensile stress levels.

(7) The microslip and small translational motion of the roller can cause regional tensile stress on the plate top surface near the roller edges in the roller track.

(8) The residual stress distributions in the neighboring subsurface material surrounding the inner and outer track boundaries are quite different from those within the deep rolling track. Significant compressive residual stresses are found on these surfaces.

(9) While the proposed FE model is shown to have significantly higher compressive residual stress compared to the published experiments representing simple roller path conditions, its qualitative aspects have not been validated directly. The model must be validated further in the future for its capability in predicting residual stress in the complex roll path conditions.

\section{Appendix}

\section{Model Validation in Simple Loading Path}

To validate the material model, a three-dimensional finite element model was built to simulate the deep rolling on $\mathrm{Ti}$ $6 \mathrm{Al}-4 \mathrm{~V}$ workpiece under simple loading path. The workpiece has a dimension of $10 \times 10 \times 80 \mathrm{~mm}$. The roller is in spherical shape as a common tool for the deep rolling under simple loading path. The diameter of roller is $6 \mathrm{~mm}$. The JohnsonCook material model and constitutive parameters for Ti-6Al$4 \mathrm{~V}$ described previously in the present paper was employed to simulate the material behavior under loading and unload conditions. The roller was assumed to be rigid to reduce the computational time since the roller is much harder than the workpiece. The model is designed to be symmetric in the later direction to simplify the simulation process and decrease the computational time. Eight-node linear brick finite elements with reduced integration and hourglass control (C3D8R) were used for the workpiece.

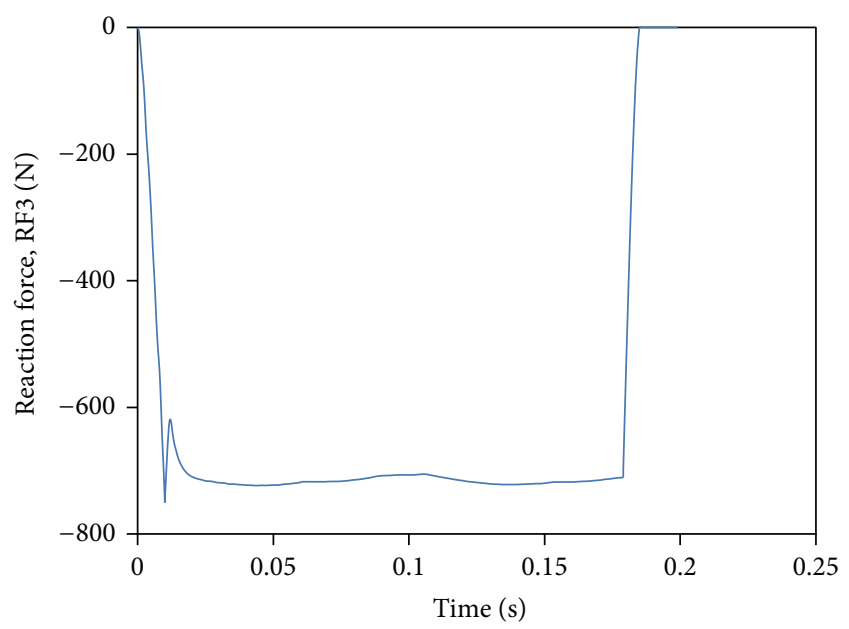

FIGURE 17: Predicted reaction force on the roller for the simple roller path.

The simulation consists of three steps. Initially, the roller sits on the starting position of the workpiece. The first step is to load the roller at its center to penetrate the workpience with a depth of $40 \mu \mathrm{m}$, the second step is to move the roller horizontally by assigning both the rotational speed of $750 \mathrm{rpm}$ and translation speed of $236 \mathrm{~mm} / \mathrm{s}$. The third step is to lift the roller after the full rolling distance of $40 \mathrm{~mm}$ is completed.

Figure 16 shows the residual stress distribution in the workpiece from the three-dimensional finite element model at the end of third step. Figure 17 shows the predicted reaction force on the roller. The average reaction force during the second step is $714 \mathrm{~N}$. Figure 18 shows the residual stress profiles ( $S 11$ and $S 22$ ) in the depth below the middle point of rolling path. Figure 19 shows a comparison of predicted residual stress $S 11$ in Figure 18 for the simple roller path to the measured residual stresses from Nalla et al. [1] and Tsuji et al. [23] for the simple roller path. The model predictions have, in terms of residual stress range, satisfactory agreement with experimental results, although there is a slight difference 


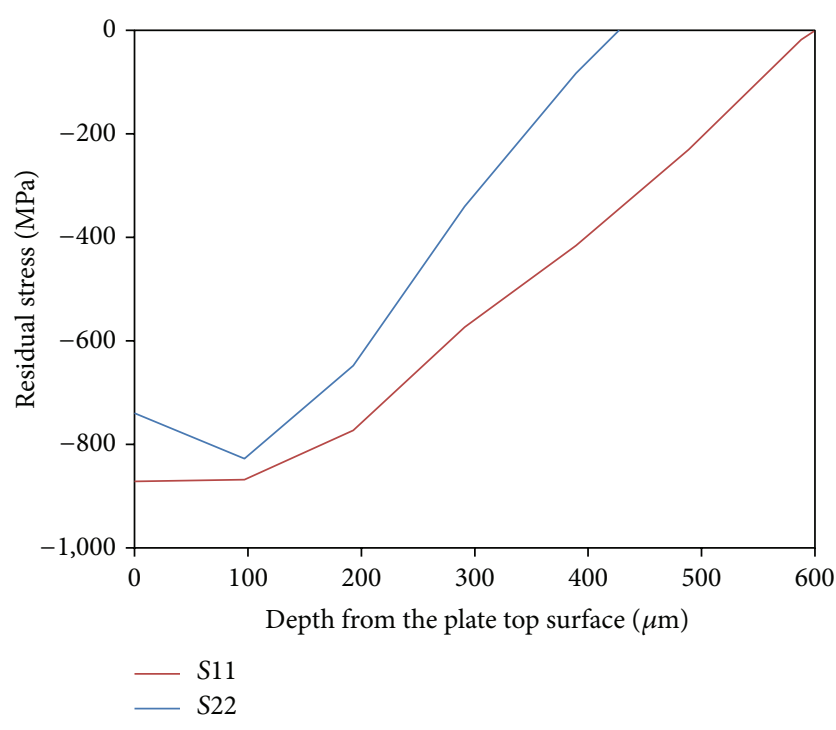

FIGURE 18: Predicted near-surface compressive residual stress for the simple roller path.

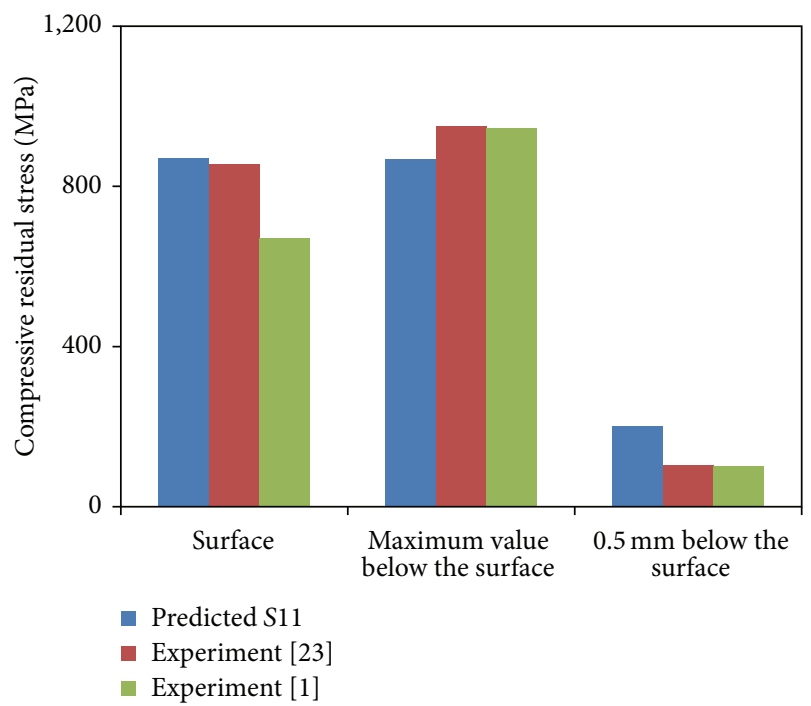

FIGURE 19: Comparison of the predicted residual stress $S 11$ from Figure 18 for the simple roller path to the measured residual stresses from $[1,23]$ for the simple roller path.

in the residual stresses between the model predictions and experimental measurements.

\section{Nomenclature}

$U 1, U 2, U 3: \quad$ Translational displacements in the $x, y$, and $z$ directions, respectively

$U R 1, U R 2, U R 3$ : Rotational displacements along the $x, y$, and $z$ axes, respectively

RF1, RF2, RF3: $\quad$ Reaction forces in the $x, y$, and $z$ directions, respectively

S11, S22, S33: $\quad$ Normal stresses in the $x, y$, and $z$ directions, respectively

S12, S13, S23: $\quad$ Equivalent to shear stresses $\tau_{x y}$, $\tau_{x z}$, and $\tau_{y z}$.

\section{Conflict of Interests}

The authors declare that there is no conflict of interests regarding the publication of this paper.

\section{Acknowledgment}

The authors would like to thank United Technologies Research Center for permission to publish this paper.

\section{References}

[1] R. K. Nalla, I. Altenberger, U. Noster, G. Y. Liu, B. Scholtes, and R. O. Ritchie, "On the influence of mechanical surface treatmentsdeep rolling and laser shock peening-on the fatigue behavior of Ti-6Al-4V at ambient and elevated temperatures," Materials Science and Engineering A, vol. 355, no. 1-2, pp. 216-230, 2003.

[2] K. S. Choi, J. Pan, and S. Ho, "Fatigue failures of rollers in crankshaft fillet rolling," SAE Technical Paper 2004-01-1498, 2004.

[3] K. S. Choi and J. Pan, "Simulations of stress distributions in crankshaft sections under fillet rolling and bending fatigue tests," International Journal of Fatigue, vol. 31, no. 3, pp. 544-557, 2009.

[4] K. H. Kloos and J. Adelmann, "Schwingfestigkeitssteigerung durch Festwalzen," Materialwissenschaft und Werkstofftechnik, vol. 19, no. 1, pp. 15-23, 1998.

[5] Y. C. Yen, P. Sartkulvanich, and T. Altan, "Finite element modeling of roller burnishing process," CIRP Annals-Manufacturing Technology, vol. 54, no. 1, pp. 237-240, 2005.

[6] P. Sartkulvanich, T. Altan, F. Jasso, and C. Rodriguez, "Finite element modeling of hard roller burnishing: an analysis on the effects of process parameters upon surface finish and residual stresses," Journal of Manufacturing Science and Engineering, Transactions of the ASME, vol. 129, no. 4, pp. 705-716, 2007.

[7] M. Y. Ali and J. Pan, "Effect of a deformable roller on residual stress distribution for elastic-plastic flat plate rolling under plane strain conditions," SAE International Journal of Materials and Manufacturing, vol. 5, no. 1, pp. 129-142, 2012.

[8] M. Guagliano and L. Vergani, "Residual stresses induced by deep rolling in notched components," Metallurgical Science and Technology, vol. 14, no. 2, pp. 61-68, 1996.

[9] K. S. Choi and J. Pan, "Effects of pressure-sensitive yielding on stress distributions in crankshaft sections under fillet rolling and bending fatigue tests," International Journal of Fatigue, vol. 31, no. 10, pp. 1588-1597, 2009.

[10] G. H. Majzoobi, K. Azadikhah, and J. Nemati, "The effects of deep rolling and shot peening on fretting fatigue resistance of Aluminum-7075-T6," Materials Science and Engineering A, vol. 516, no. 1-2, pp. 235-247, 2009.

[11] C. H. Fu, Y. B. Guo, J. McKinney, and X. T. Wei, "Process mechanics of low plasticity burnishing of nitinol alloy," Journal of Materials Engineering and Performance, vol. 21, no. 12, pp. 2607-2617, 2012.

[12] M. Sayahi, S. Sghaier, and H. Belhadjsalah, "Finite element analysis of ball burnishing process: comparisons between numerical results and experiments," International Journal of Advanced Manufacturing Technology, vol. 67, no. 5-8, pp. 1665-1673, 2013.

[13] F. Klocke, V. Bäcker, H. Wegner, and M. Zimmermann, "Finite element analysis of the roller burnishing process for fatigue resistance increase of engine components," Proceedings of the Institution of Mechanical Engineers, Part B: Journal of Engineering Manufacture, vol. 225, no. 1, pp. 2-11, 2011. 
[14] R. M. Guo, "Investigation of roll bite behavior with various cold rolling conditions using semi-analytic solutions of von Karman's rolling equation," La Metallurgia Italiana, vol. 2014, no. 4, pp. 29-38, 2014.

[15] F. Mohammadi, R. Sedaghati, and A. Bonakdar, "Finite element analysis and design optimization of low plasticity burnishing process," International Journal of Advanced Manufacturing Technology, vol. 70, no. 5-8, pp. 1337-1354, 2014.

[16] F. D. Fischer and G. Schleinzer, "Residual stress formation and distortion of rail steel," in Handbook of Residual Stress and Deformation of Steel, G. E. Totten, M. Howes, and T. Inoue, Eds., pp. 424-436, ASM International, Material Park, Ohio, USA, 2002.

[17] L. Taylor, J. Cao, A. P. Karafillis, and M. C. Boyce, "Numerical simulations of sheet-metal forming," Journal of Materials Processing Technology, vol. 50, no. 1-4, pp. 168-179, 1995.

[18] SIMULIA, ABAQUS User's Manual, Version 6.12, SIMULIA, Providence, RI, USA, 2012.

[19] F. Klocke, Manufacturing Processes, 1, Cutting, Springer, Berlin, Germany, 2011.

[20] L. Li and N. He, "A FEA study on mechanisms of saw-tooth chip deformation in high speed cutting of Ti-6Al-4V alloy," in Proceedings of the 5th International Conference on High Speed Machining, pp. 759-767, 2006.

[21] H. L. Heathcote, "The ball bearing: in the making, under test and on service," Proceedings of the Institute of Automobile Engineers, vol. 15, no. 1, pp. 569-702, 1921.

[22] K. L. Johnson, Contact Mechanics, Cambridge University Press, New York, NY, USA, 1987.

[23] N. Tsuji, S. Tanaka, and T. Takasugi, "Evaluation of surfacemodified Ti-6Al-4V alloy by combination of plasma-carburizing and deep-rolling," Materials Science and Engineering A, vol. 488, no. 1-2, pp. 139-145, 2008. 

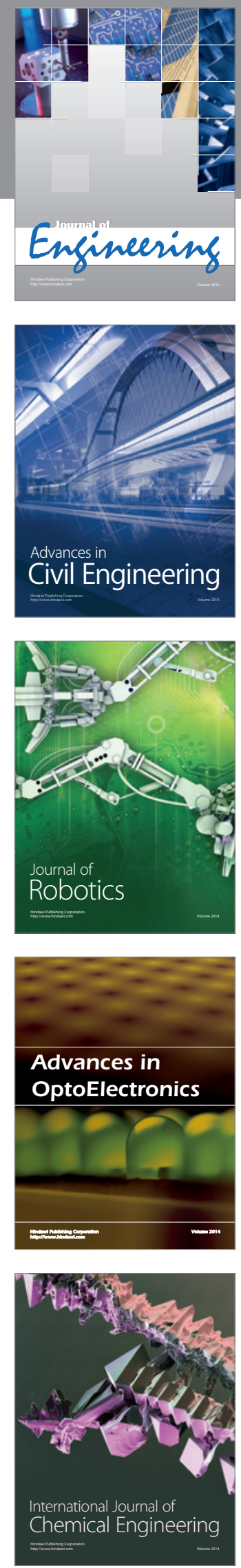

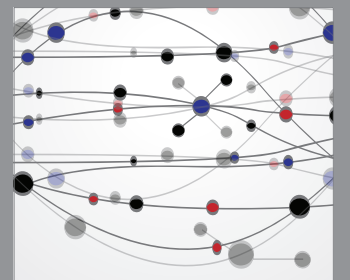

The Scientific World Journal
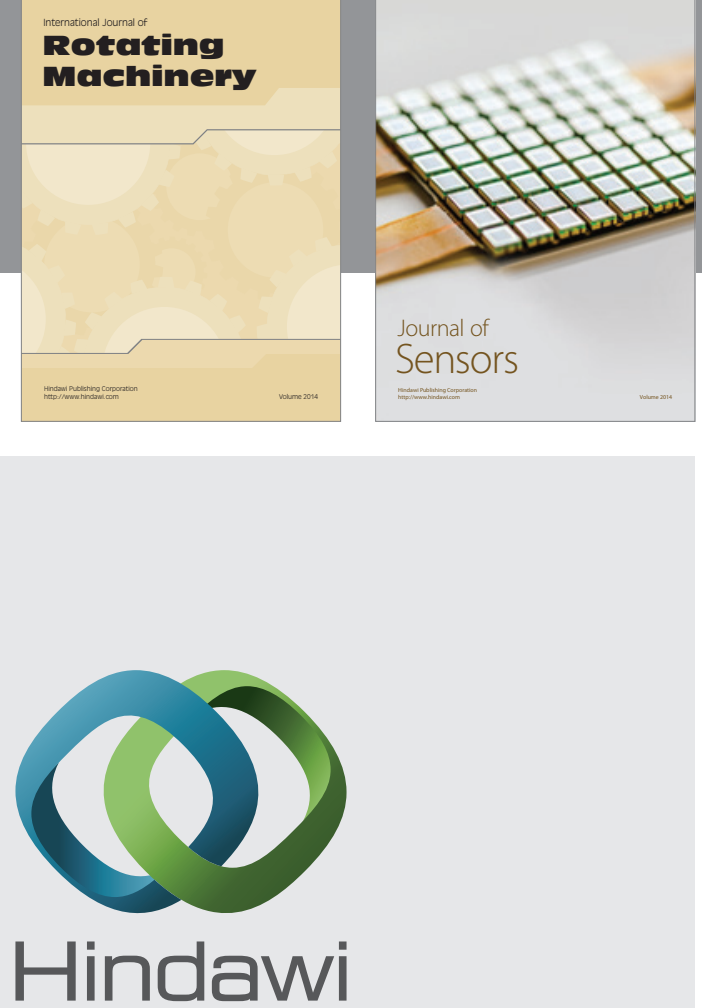

Submit your manuscripts at http://www.hindawi.com
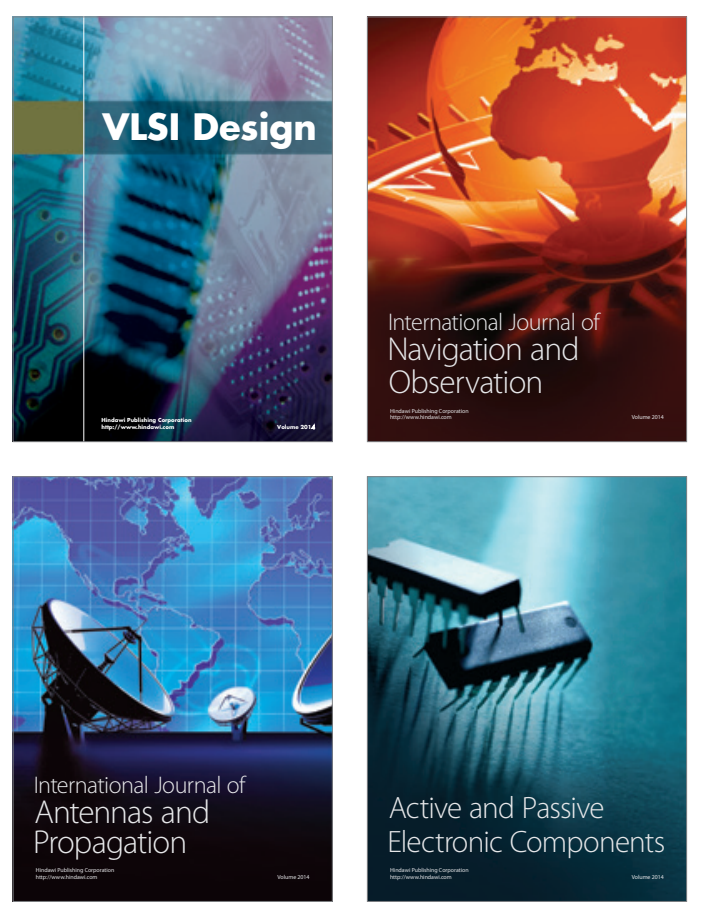
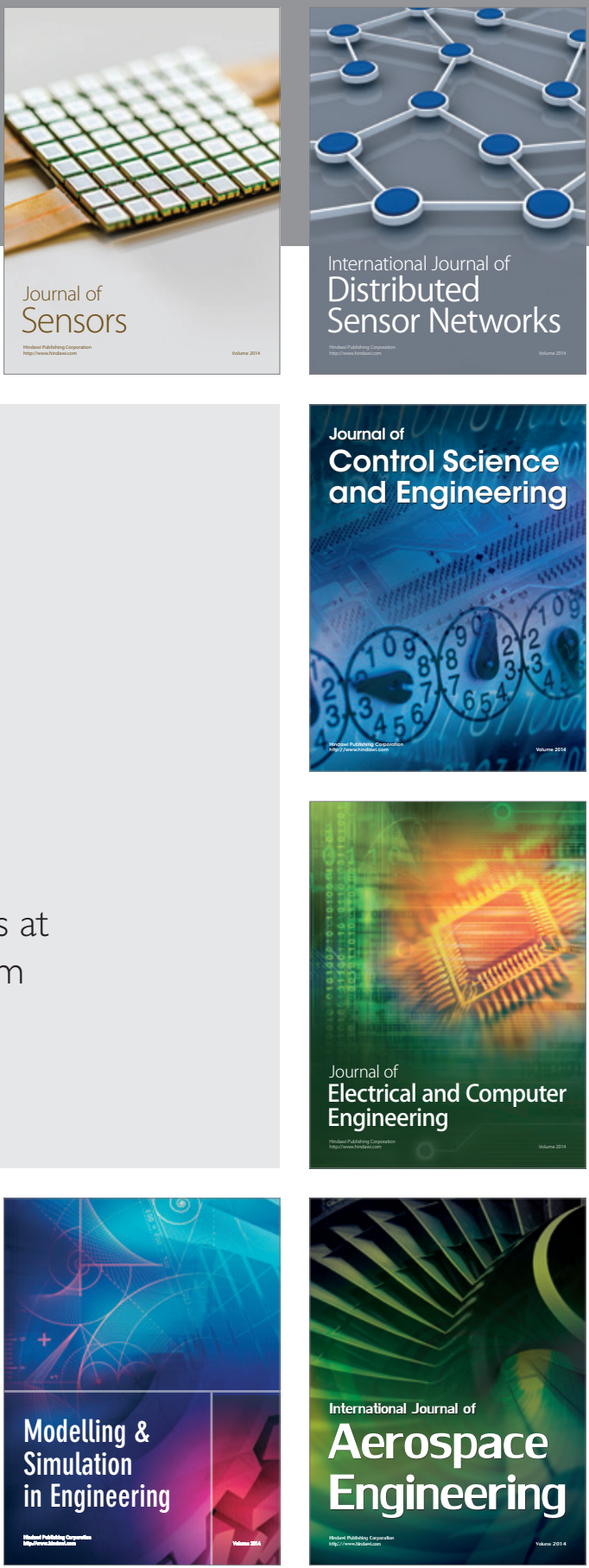

Journal of

Control Science

and Engineering
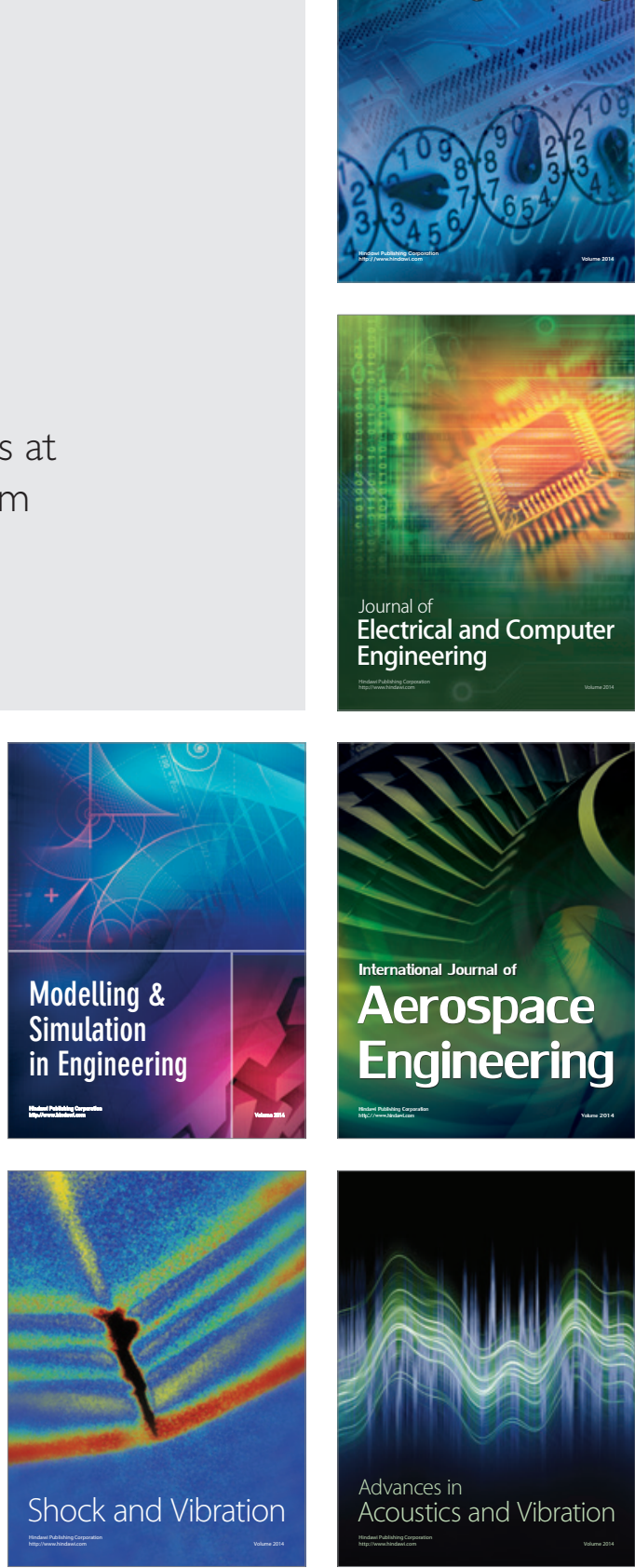